\title{
Identification of factors affecting sustainable development of renewable energy sources in transport
}

\author{
Leontiy Eder ${ }^{1,2}$, Irina Filimonova ${ }^{1,2}$, Vasily Nemov $^{1,2}$, Anna Komarova ${ }^{1,2}$, and Vladislav Kozhevin ${ }^{2}$ \\ ${ }^{1}$ Trofimuk Institute of Petroleum Geology and Geophysics SB RAS, Russia \\ ${ }^{2}$ Novosibirsk State University, Russia
}

\begin{abstract}
At present motor transport is one of the key components of the formation of a long-term policy of sustainable economic development. Analysis of the structure of energy consumption in motor transport is necessary for better understanding of the factors that affect the increase in the share of renewable energy sources in transport and the effectiveness of specific support measures for the transition to vehicles with minimal or no greenhouse gas emissions. Models of pooled regression, regression with random and fixed effects were built in order to reveal the influence of the chosen factors on the share of renewable energy and electricity in the structure of energy consumption by vehicles. The results of evaluation for 31 European countries in the 2005-2017 showed that the criterion, which allows identifying groups of countries, is the volume of environmental transport taxes per vehicle unit. Countries with higher taxation volumes has such influencing factors as Corruption Perceptions Index, Energy productivity, Total environmental taxes per capita and Employment in high- and medium-high technology manufacturing sectors and knowledgeintensive service sectors. Consumption in countries with lower tax differentiation is influenced by index of research intensity, Corruption Perceptions Index and Shares of environmental and labour taxes.
\end{abstract}

\section{Introduction}

Analysis of the present state and structure of energy consumption is a key component in the formation of long-term policies for sustainable development of the economy [1]. Currently, an important aspect is the relationship between motor vehicles and pollution. Reduction of the negative impact on the environment and human health is associated with the improvement of automotive technologies and the transition to alternative fuels in road transport, primarily electricity and renewable sources [2].

In order to reduce the emission of greenhouse gases, European countries have set targets for efficiency of energy consumption, which were achieved, as well as increase the usage of renewable energy sources, thus becoming world leaders in this area.

By 2020, the goal is set for energy consumption to be at least $20 \%$ from renewable sources (Directive $2009 / 28 / \mathrm{EC}$ ) and at least $27 \%$ by 2030 (2030 Energy Strategy). However, in 2016, the consumption of oil products by vehicles in the European Union was 95\%. Moreover, according to the European Environment Agency (EEA), the amount of greenhouse gas emissions due to fuel combustion in motor transport increased by $5.4 \%$ in the period of 2013-2016.

An analysis of the structure of energy consumption in motor transport is necessary for better understanding of the factors that affect the increase in the share of renewable energy sources in transport and the effectiveness of specific support measures for the transition to vehicles with minimal or no greenhouse gas emissions. In addition, some researchers [3] believe that electrical energy consumption in transport will increase significantly, so its role must be taken into account to adequately provide the population with electricity. For example, in North Europe countries (Denmark, Norway, Iceland, Sweden and Finland), electric vehicle sales increased by $57 \%$ in 2017 compared to the previous year [4]. At the same time, the improvement of technologies leads to an increase in the energy efficiency of traditional engines and to a certain reduction in the demand for petroleum products $[5,6]$

The object of the study is renewable energy sources in the fuel balance of the motor transport.

The purpose of the study is identification of the factors determining the level and dynamics of consumption of renewable energy resources.

The objectives of the study include: 1) analysis of the main trends in energy consumption on motor transport; 2) identification of factors affecting the level and dynamics of consumption of renewable energy sources; and 3) building of a multifactor model of the influence of the identified factors on the consumption of renewable energy sources using panel data.

Scientific novelty of research consists of identification of main factors affecting the consumption renewable energy sources on road transport, including institutional features of countries, tax incentives and the level of technological development; building of multi- 
factor model based on established and systematized indicators with following verification of the significance of factors.

With the development of infrastructure and the improvement of the operational and economic characteristics of cars using alternative fuels, the attractiveness of renewable energy sources is increasing. The share of biofuels in the structure of energy consumption by motor transport in the world is about $4 \%$. Thus, it represents a large share of the renewable energy in the structure of demand for transport energy. In addition, renewable energy in transport is represented by cars using natural gas and electricity [7]. According to British Petroleum [8], the number of electric vehicles will increase from 1.2 million in 2015 to 100 million in 2035 , which is $6 \%$ of the world's fleet.

The study of demand for cars using alternative energy sources was carried out by Mabit [9], using such factors as price, annual costs, acceleration time and operating range.

In addition to forecasting demand for cars using alternative fuels, researchers are trying to predict their impact on oil consumption. Oil is the main energy carrier in transport, and the main obstacle to the introduction of renewable fuel. The dependence of investments in alternative energy sources on oil prices, real GDP and interest rates is described with the help of vector regression in the work of Shah, Hiles and Morley [10]. Sadorsky in "Modeling renewable energy consumption for a greener world economy" also uses vector autoregression to analyze the relationship between alternative energy consumption, income, oil consumption and oil prices [11].

As shown in the studies of the International Energy Agency "Nordic EV Outlook 2018" [4], "Global EV Outlook 2018. Towards cross-modal electrification", one of the most important factors affecting the decision to buy a car with low or zero emissions is taxes on the car purchase, such as differentiated VAT rates, vehicle registration tax depending on the amount of $\mathrm{CO}_{2}$ emissions. Thus, a differentiated level of taxation depending on the environmental characteristics of the car, make it economically feasible to purchase cars with better environmental performance or alternative power units.

To analyze the structure of energy consumption in motor transport and identify significant factors for countries with different levels of environmental taxes on transport, a grouping of countries was carried out. The division into groups is based on the indicator of the level

\section{Data}

The model is based on data from 31 European countries. The database was formed from the statistics of Eurostat, World Bank's World Development Indicators and International Energy Agency data. The observation period under study is between 2005 and 2017

The following factors that could influence the consumption of renewable energy sources in motor transport were analyzed: the prices for traditional motor fuel, tax incentives, the degree of development of the institutional environment and technologies. Specific indicators that reflect these factors are: prices for traditional motor fuel - the cost of motor gasoline; tax incentives - total volume of environmental taxes per capita and shares of environmental and labor taxes in total tax revenues; the degree of development of the institutional environment - the index of perception of corruption; the level of technology development - the energy efficiency of the economy, share of employed in high- and medium-high technology manufacturing sectors and knowledge-intensive service sectors and the share of R \& D in the GDP structure.

Share of renewable energy and electricity in the structure of energy consumption by vehicles was chosen as a dependent variable.

\section{Methodology}

Models based on panel data are among approaches for building models of the dependence of variables on various factors. The panel data combines both spatial type data and time series data.

In general, the regression model of panel data has the following form [12, 13]:

$$
x_{i t}=Z_{i t} \alpha_{i t}+\varepsilon_{i t}
$$

where $\mathrm{i}$ denotes index of economic unit, $\mathrm{t}$ - time period, $\propto_{i t}$ - the coefficients of the explanatory variables of vector $Z_{i t}$ in the time period $t$ for the unit $i, \varepsilon_{i t}-$ vector of errors.

This model cannot be estimated, but it is possible to isolate specific factors that are related to a particular economic object at a certain point in time, consequently individual (specific) features can be evaluated.

$$
x_{i t}=Z_{i t} \propto_{i t}+\gamma_{t}+f_{i}+\varepsilon_{i t}
$$

with $Z_{\text {it }}$ denoting n-dimensional vector of independent variables without constant, $f_{i}-$ individual features that do not depend on time, $\gamma_{t}$ - specific features that are not observed in all periods, but for all objects, $\varepsilon_{\text {it }}$ - independent, identically distributed random variables (both in individuals and in time) with zero mathematical expectation and variance $\sigma_{\varepsilon}^{2}$.

Depending on the assumptions about the nature of $f_{i}$, models with fixed ( $f_{i}$ are $\mathrm{N}$ constant unknown parameters) and random effects $\left(f_{i}\right.$ are random and not correlated with errors) are distinguished.

To choose between model with fixed-effect, pooled regression, and model with random effects a Wald test, Breusch-Pagan test and Hausman test are performed.

Once the relationship model of the dependent variable and factors has been obtained, it is necessary to estimate its accuracy with the help of the determination coefficient, showing how well the obtained regression describes the dependent variable and accounting to be at least 50\%.

Further, it is necessary to check statistical significance of the obtained regression with the help of F-statistic on $5 \%$ significance level. The presence of multicollinearity can be verified using the coefficients of pair correlation. If the factor correlation coefficient is large, then there is a connection between these factors. 


\section{Empirical testing}

Two models were developed on the bases of different dependent variables determining the share of RES in the energy consumption structure in transport sector. The division of the observed countries into two groups was established in the course of the analysis and confirmed by regression calculations with dummy variables. Group one consists of countries with environmental taxes by economic activity per capita greater than 200 euro and second group - less than 200 euro.

All the developed models show robust results with significant F-statistic, presenting significance of the best in-group models - for (I) pooled regression F-statistic equals 30.94, for (II) pooled regression F-statistic equals 14.20.

Based on the data for the European countries and (I) model, three models were built: a pooled regression, model with fixed effects, and model with random effects (Table 1). The model of cross-sectional regression is based on the assumption that all the studied countries are identical, thus, a normal multifactorial regression was built.

Table 1. Assessment of the model for the economies of 12 European countries from group one (significance level 0.05)

\begin{tabular}{|l|c|c|c|}
\hline \multicolumn{1}{|c|}{ Variable } & Pooling & Random & Fixed \\
\hline (Intercept) & $-8.44^{* * *}$ & $-7.50^{* * *}$ & \\
\hline $\begin{array}{l}\text { Logarithm } \\
\text { (EMPL_INTENS_SECT) }\end{array}$ & 0.71 & $0.77^{*}$ & -1.44 \\
\hline $\begin{array}{l}\text { Logarithm } \\
\text { (ENERGY_PRODUCTIVITY) }\end{array}$ & $0.87^{* * *}$ & $1.34^{* * *}$ & $1.93^{* * *}$ \\
\hline Logarithm (CPI) & $1.83^{* *}$ & $2.26^{* *}$ & 0.81 \\
\hline $\begin{array}{l}\text { Logarithm } \\
\text { (ENV_TAX_PER_CAP) }\end{array}$ & -0.44 & $-1.04 *$ & $-1.58^{* *}$ \\
\hline $\mathrm{R}^{\wedge} 2$ & 0.39 & 0.69 & 0.34 \\
\hline Adj. R^2 & 0.34 & 0.67 & 0.12 \\
\hline F-statistic & 8.69 & 30.94 & 5.71 \\
\hline
\end{tabular}

Comparison of the determination coefficient of the models shows total dominance of random effects regression model $(\mathrm{R}-\mathrm{Squared}=0.69$ ), while fixed effects $(\mathrm{R}-$ Squared $=0.34)$ and polling $(\mathrm{R}$-Squared $=0.39)$ show lower efficiency, but in general it is not efficient approach. Then the most suitable model was chosen by Wald, Breusch-Pagan and Hausman tests and F-statistic random effects model (Table 2).

According to the F- statistic, the model is significant (p-value is less than $1.68 \mathrm{e}-13$ for random effects regression). All observed factors are significant at 5\% level.

Table 2. Tests of models (significance level 0.05)

\begin{tabular}{|l|c|c|c|c|}
\hline \multicolumn{1}{|c|}{ Test } & Df & Chisq & p-value & Best model \\
\hline Wald & 1 & 47.34 & $2.2 \mathrm{e}-16$ & Fixed \\
\hline Breusch-Pagan & 1 & 43.59 & $4.0 \mathrm{e}-11$ & Random \\
\hline Hausman & 4 & 8.71 & 0.07 & RE and FE \\
\hline
\end{tabular}

Based on the data for the European countries and (II) model, three models were built: a pooled regression, model with fixed effects, and model with random effects (Table 3).

Table 3. Assessment of the model for the economies of 12 European countries from group two (significance level 0.05)

\begin{tabular}{|l|c|c|c|}
\hline \multicolumn{1}{|c|}{ Variable } & Pooling & Random & Fixed \\
\hline \multicolumn{1}{|c|}{ (Intercept) } & $5.11^{* * *}$ & 2.74 & \\
\hline Logarithm (RD_GDP) & $0.24^{* *}$ & 0.24 & $0.40^{*}$ \\
\hline Logarithm (CPI) & -0.51 & 0.09 & $0.97^{*}$ \\
\hline $\begin{array}{l}\text { Logarithm } \\
\text { (ENV_TAX_PER_CAP) }\end{array}$ & $-0.85^{* * *}$ & $-0.87^{* *}$ & $-1.55^{* * *}$ \\
\hline $\mathrm{R}^{\wedge} 2$ & 0.41 & 0.29 & 0.44 \\
\hline Adj. R`2 & 0.38 & 0.25 & 0.27 \\
\hline F-statistic & 14.20 & 8.11 & 12.78 \\
\hline
\end{tabular}

Comparison of the determination coefficient of the pooled regression model $(\mathrm{R}$-Squared $=0.41)$ and fixed effects (R-Squared $=0.44$ ) show that the estimates obtained are much efficient than the estimates of the random effects model $(\mathrm{R}-\mathrm{Squared}=0.29)$. Then the most suitable model was chosen by Wald, Breusch-Pagan and Hausman tests - model with fixed effects (Table 4).

According to the F- statistic, the model is significant (p-value is less than 3.98e-07). All observed factors are significant at $5 \%$ level.

Table 4. Tests of models (significance level 0.05)

\begin{tabular}{|c|c|c|c|c|}
\hline Test & Df & Chisq & p-value & Best model \\
\hline Wald & 1 & 14.28 & $1.6 \mathrm{e}-04$ & Fixed \\
\hline Breusch-Pagan & 1 & 44.51 & $2.53 \mathrm{e}-11$ & Random \\
\hline Hausman & 3 & 1.31 & 0.72 & RE and FE \\
\hline
\end{tabular}

\section{Discussion}

The main energy source for motor transport is oil products, which share in total consumption is $94 \%$. At the same time, consumption of alternative fuels such as biofuels, electricity and natural gas is growing. The consumption of renewable energy sources (RES) in motor transport is influenced by various groups of factors: economic, cost, and infrastructure. However, the high cost of cars with zero or low $\mathrm{CO}_{2}$ emissions is the main limiting factor for increasing the share of renewable energy sources in motor transport.

The analysis showed that the studied countries have a different elasticity of the share of RES in motor transport by the chosen factors. Thus, in the first group of countries there is a high sensitivity of the share of RES to the change in institutional and technological factors, while in the second group of countries the factors under study weakly stimulate the use of RES. The study showed that the criterion, which allows identifying these groups of countries, is the volume of environmental transport taxes per vehicle unit. Ecological taxation in transport includes such payments as Registration or use of motor vehicles, recurrent (e.g. yearly taxes), Road use (e.g. motorway taxes), Congestion charges and city tolls, and others. The average value of environmental taxes per vehicle unit in the surveyed countries ranges from 17 euros (Estonia) to 1700 euros per year (Denmark). 
The first group included countries with an average level of environmental taxes of more than 200 euros per car. These are, first of all, the countries of Northern Europe (Denmark, Norway, etc.) and Central Europe (Germany, Netherlands, Belgium, etc.), as well as Great Britain, Croatia and Cyprus. The second group of countries with an average level of environmental taxes of less than 200 euros per car is primarily the countries of Eastern Europe (Czech Republic, Bulgaria, Hungary, Slovakia, etc.), as well as some countries in Southern and Western Europe (Portugal, Spain, Italy) .

Significant factors for the first group of countries were: Corruption Perceptions Index, Energy productivity, Total environmental taxes per capita and Employment in high- and medium-high technology manufacturing sectors and knowledge-intensive service sectors. For the second group of countries, the index of research intensity, Corruption Perceptions Index and Shares of environmental and labor taxes were the significant factors.

Differentiated tax rates (depending on the environmental characteristics of the car) allow for overcoming of the barrier of high initial cost of cars with low or zero greenhouse gas emissions. This leads to a greater variability in the demand for RES in response to a change in various factors.

In countries with a high level of environmental charges, the most significant factor is the degree of development of institutions. Hence, high ecological taxes on motor transport do not always lead to the expected impact on the growth of consumption of renewable energy sources. However, there is a significant increase in the share of RES and reduction of greenhouse gas emissions by vehicles in countries with high quality institutions, the introduction of a taxation system depending on the environmental characteristics of cars, coupled with incentives such as free parking, access to lanes dedicated for buses, exemption from payment for the use of regional toll roads, etc.

The second significant factor for the first group of countries is energy productivity. This indicator characterizes the policy of the state and the effectiveness of measures taken in the matters of energy conservation and ecology. The high efficiency of measures to increase energy efficiency promotes the introduction of advanced technologies in all sectors of the economy and, as a result, the growth of the use of safer energy sources. The third significant factor is total environmental taxes per capita. Higher tax burden per capita on all sectors of the economy in the field of ecology stimulates the use of technologies and energy carriers with the least impact on the environment.

For all groups of countries, the level of technological development of the country is a significant factor represented by the share of renewable energy sources: employment in high- and medium-high technology manufacturing sectors and knowledge-intensive service sectors and the indicator of the science intensity of the economy.

The specific significant factor for the second group of countries is Shares of environmental and labor taxes in total tax revenues. At the same time, an increase in the share of environmental taxes leads to a decrease in the use of renewable energy sources. Thus, in countries where there are no transport taxes that remove the barrier of high initial cost of environmentally safe vehicles, an increase in other environmental taxes results in a reduction of the well-being of the population and increase in the usage of traditional, cheaper types of engines that burn petroleum products.

\section{Conclusion}

One of the most important factors affecting the use of renewable energy sources for motor transport is the volume of transport environmental taxes per vehicle unit, which allow removing the barrier of high initial cost of high-tech vehicles. In countries with high levels of environmental taxes and differential tax rates, factors such as employment in high- and medium-high technology manufacturing sectors and knowledgeintensive service sectors, the total volume of environmental taxes in the economy per capita have a significant influence on the decision-making in favour of RES in transport. In countries without substantial transport taxes, the specific significant factor for the second group of countries is shares of environmental and labour taxes in total tax revenues. Thus, an increase in other environmental taxes leads to a decrease in the wellbeing of the population and the use of traditional, cheaper types of engines that burn petroleum products.

The research was supported by the RFBR grant 17-0600537 and grant of the President of Russian Federation MD-6476.2018.6.

\section{References}

1. BP Energy Outlook. BP, 2017.

2. I.S. Imran Hussain, C. Hiles, B. Morley, How do oil prices, macroeconomic factors and policies affect the market for renewable energy. Applied Energy, vol. 215(C), 2018.

3. Nordic EV outlook 2018. International Energy Agency, 2018.

4. P. Sadorsky. Modeling Renewable Energy Consumption for a Greener Global Economy. Planet Earth, 2011.

5. S. L. Mabit. Danish preferences concerning alternative-fuel vehicles. Procedings ETC, 2009.

6. Y. He, Q. Zhang, Y. Pang, The development pattern design of Chinese electric vehicles based on the analysis of the critical price of the life cycle cost. Energy policy, vol. 109(C), 2017.

7. L. Eder, I. Provornaya, Analysis of energy intensity trend as a tool for long-term forecasting of energy consumption. Energy Efficiency, 2018.

8. L. Eder, I. Filimonova, V. Nemov, I. Provornaya, Forecasting sustainable development of transport sectors of Russia and EU: Energy consumption and efficiency. International Journal of Energy Economics and Policy, 8(2), 2018. 
9. L. Eder, V. Nemov, Forecast of energy consumption of vehicles. Studies on Russian Economic Development, 28(4), 2017.

10. L. Eder, I. Filimonova, V. Nemov, I. Provornaya, Forecasting of energy and petroleum consumption by motor transport in the regions of the Russian Federation. Economy of Region, 13(3), 2017.

11. A. Kontorovich, M. Epov, L. Eder, Long-term and medium-term scenarios and factors in world energy perspectives for the 21st century. Russian Geology and Geophysics, 57(12), 2014.

12. E. Kolomak, Panel data: methods of econometric analysis: textbook. Novosibirsk: Editorial and publishing center of NSU, 2011.

13. T. Ratnikova, K. Furmanov, Analysis of panel data and data on the duration of States: studies manual. Moscow: Publishing house of the Higher School of Economics, 2014. 